\title{
28 Research Square \\ Locoregional Treatment in De Novo Metastatic Breast Cancer: A Retrospective Cohort Study
}

\section{Sun Jianna}

Cangzhou Clinical College of Integrated Traditional Chinese Medicine and Western Medicine of Hebei Medical University

\section{Kong Lingjun}

Cangzhou Clinical College of Integrated Traditional Chinese Medicine and Western Medicine ofHebei Medical University

\section{Feng Nana}

Cangzhou Clinical College of Integrated Traditional Chinese Medicine and Western Medicine of Hebei Medical University

\section{Liu Hong}

Tianjin Medical University

\section{Ren Chongxi ( $\sim$ rcxvip@outlook.com )}

Cangzhou Clinical College of Integrated Traditional Chinese and Western Medicine of Hebei Medical University

\section{Research}

Keywords: De novo metastatic breast cancer, Locoregional therapy, Primary tumor surgery, Surgical timings and surgical margins, Overall survival

Posted Date: December 15th, 2020

DOI: https://doi.org/10.21203/rs.3.rs-125308/v1

License: (a) (i) This work is licensed under a Creative Commons Attribution 4.0 International License. Read Full License 


\section{Abstract}

Background: In an earlier analysis of this cohort study, local therapy based on surgical resection of the primary tumor might confer a survival benefit in women with de novo metastatic breast cancer (dnMBC). Here we report the survival outcomes of locoregional treatment (LRT), focusing on the association of surgical timings and surgical margins with survival in these patients.

Methods: The retrospective study included patients with dnMBC in two Chinese tertiary hospitals, between March 1, 2007, and December 31, 2017. Overall survival (OS) was evaluated by means of a stratified log-rank test and summarized with the use of Kaplan-Meier methods.

Results: A total of 153 patients were included, of whom 87 underwent LRT and 66 systemic therapy alone (STA). LRT showed a significant OS benefit over STA (HR, 0.47; $95 \% \mathrm{Cl}, 0.33$ to $0.69 ; \mathrm{p}<.0001)$. Median OS of LRT group and STA group were 42 months ( $95 \% \mathrm{Cl}, 35.0$ to 48.9 months) and 21 months $(95 \% \mathrm{Cl}, 16.1$ to 25.9 months), respectively. The benefit was consistent across most subgroups. The OS of patients undergoing surgery was better than that of patients without surgery $(\mathrm{HR}, 0.48 ; 95 \% \mathrm{Cl}, 0.33$ to 0.70 ; $\mathrm{p}=.0001$ ), and there was difference in survival improvement at different surgical timings (surgery before chemotherapy, during chemotherapy and after chemotherapy) (HR, $0.79 ; 95 \% \mathrm{Cl}, 0.65$ to $0.95 ; \mathrm{p}=.013)$. The survival benefit of surgery after chemotherapy was the most, followed by surgery during chemotherapy (Median 56 months, $95 \% \mathrm{Cl}, 40.8$ to 71.2 months). Moreover, compared with patients with positive margins, the OS of patients with negative margins was significantly improved $(\mathrm{HR}, 2.35 ; 95 \% \mathrm{Cl}$, 1.65 to 3.35 ; $p<.0001$ ), with a median OS of 56 months ( $95 \% \mathrm{Cl}, 45.9$ to 66.1 months).

Conclusions: Our results suggest that LRT is associated with improved OS in women with dnMBC, and patients who had surgery after or during systemic chemotherapy with negative surgical margins, are expected to benefit more.

\section{Highlights}

\section{Background}

To date, the role locoregional treatment for de novo metastatic breast cancer ( $\mathrm{dnMBC}$ ) patients is still ambiguous and no consensus exists;

Whether locoregional treatment will affect overall survival (OS) of patients with dnMBC, previous prospective studies have shown conflicting results;

The debate about locoregional treatment in patients with dnMBC persists.

\section{Findings}

Locoregional treatment was associated with improved OS in women with dnMBC; 
The OS of patients undergoing surgery was better than that of patients without surgery;

For surgical patients, both the surgical timings and the surgical margins were associated with OS;

Patients who underwent surgery after or during systemic chemotherapy with negative surgical margin benefited more from $0 S$.

\section{Implications}

This study provides additional evidence that patients with dnMBC could benefit from locoregional treatment.

\section{Background}

De novo metastatic breast cancer ( $\mathrm{dnMBC}$ ) refers to patients with metastatic breast cancer at initial diagnosis, and has been reported that approximate $10 \%$ of newly diagnosed breast cancer patients present with distant metastases ${ }^{[1-3]}$. This group of patients with dnMBC makes up about $3-8 \%$ of new breast cancer diagnoses in the USA and Western ${ }^{[1,4]}$, and $3-5 \%$ of these patients in China ${ }^{[5]}$. Their overall survival (OS) was approximately 16 to 29 months ${ }^{[6]}$. For several decades treatment of advanced breast cancer has been challenged by lack of reliable therapeutic options. As with other advanced cancers, it is considered an incurable disease and significantly longer OS with the best possible quality of life is the ultimate goal for the treatment ${ }^{[7,8]}$. In the last few years, although the therapeutic strategy for advanced breast cancer has undergone changes, systemic therapy has remained the cornerstone of treatment in patients with dnMBC. Similarly, although many articles have suggested progressive improvement in OS for patients with metastatic breast cancer, a recent analysis has showed that metastatic survival has barely budged in recent decades ${ }^{[9]}$; It appears from these results that we may be at a crossroads for dnMBC treatment and survival ${ }^{[10]}$. As a result, the association of primary site local therapy in these patients with survival has received a great deal of attention at the same time. However, whether locoregional therapy (LRT, surgery and/or radiotherapy) should be performed in this patient population has been debated to date.

The current practice guidelines for the role of breast surgery in stage IV disease from the ESMO Guidelines and the NCCN Guidelines recommended different points ${ }^{[11]}$. From the NCCN guidelines (version 3,2020$)^{[12]}$, the primary treatment approach for patients with dnMBC is systemic therapy, with consideration of LRT after initial systemic treatment for those patients requiring palliation of symptoms or with impending complications, such as skin ulceration, bleeding, fungation, and pain. ESMO Guidelines suggested that the true value of LRT was currently unknown and recommended that it could be considered in selected patients. In addition, ESMO (4nd edition) guidelines for advanced breast cancer pointed out that until there was more supporting evidence, it was not advocated to routinely perform aggressive surgery in patients with dnMBC ${ }^{[13]}$. Nevertheless, a large number of retrospective data show that breast surgeons worldwide had done primary tumor surgery on patients who had dnMBC although 
there was no robust evidence ${ }^{[14]}$. The results of many previous studies have been contradictory: some researchers suggested that local therapy might improve the prognosis in patients with dnMBC ${ }^{[8,15-20]}$. A recent publication by Ritika Gera et al. ${ }^{[21]}$ found that LRT was associated with an OS benefit in dnMBC patients. Other researchers observed that primary resection did not improve outcomes of these patients [22-26]. Several studies have similarly reported that certain patients, such as those who are younger and have bone-only metastasis, may benefit from LRT ${ }^{[27-30]}$. Although stage IV breast cancer is not curable, advances in systemic therapy have contributed to improved survival, which has prompted breast surgeons to question whether more aggressive LRT can favorably affect clinical outcomes. Over the past few decades, multiple retrospective data from single institutions and large databases (USA, Europe or Asia) have suggested that LRT may have survival benefit, confirmed by five meta-analyses ${ }^{[21,31-34]}$. Until recently, however, only three published prospective studies have assessed the impact of LRT in dnMBC [35-37]; and these studies have shown conflicting results. The debate about LRT in patients with dnMBC persists ${ }^{[38]}$.

In the primary analysis of a previous cohort study ${ }^{[19]}$, local therapy based on surgical resection of the primary tumor resulted in significantly longer OS than systemic therapy alone (STA) in patients with dnMBC. Results for OS were not yet mature at the time of the primary analysis (median, 38 vs. 19 months; $0.50 ; 95 \% \mathrm{Cl} 0.34-0.73)$. Moreover, the timings of surgery and surgical margins were not discussed for patients undergoing surgery in the trial. Here, we report the results from the updated survival analysis, in particular the association of surgical timings and surgical margins with OS in this patient population.

\section{Methods}

\section{Study design and patients}

We previously conducted a retrospective cohort study to investigate the clinicopathological profile and survival outcomes of local therapy based on surgical resection of the primary tumor in female patients with $\mathrm{dnMBC}$. The design and details of the study were previously reported ${ }^{[19]}$, and the information was supplemented and updated. The current analysis, performed within the same dataset, aimed to further assess the survival impact of LRT, focusing on the association of surgical timing and surgical margin with OS in these patients. Patients were included in the analysis if they met the following criteria: 1) had clear histological evidence at initial diagnosis; 2 ) identified with metastases by clinicopathological or radiological evidence at the time of being diagnosed with breast cancer; 3) metastases were identified according to the American Joint Commission of Cancer (AJCC) 7th edition staging criteria; 4) did not receive any prior treatment; 5) no other malignancies were present; and 6) had follow-up of more than 3 months. Patients with recurrent metastases and incomplete or refusal to provide follow-up information were excluded; patients who had received any previous treatment for advanced disease were not enrolled. The study was approved by the local clinical research ethics committees (NO. 2017-AF29-058). The study was conducted in accordance with Declaration of Helsinki. 
Treatment information, including LRT and STA, was recorded and analysed. Surgical treatment of primary tumors, alone or in combination with radiotherapy, refered to LRT. STA was defined as the use of any chemotherapy, endocrine therapy, and/or anti-HER2 target therapy. OS, as primary end point, was defined as days from diagnosis to last clinic visit day or day of death. OS results in this analysis are for all eligible patients with dnMBC. Secondary outcomes included timing of surgery, surgical margin involvement, and utilization of radiation therapy (RT). In this study, the timing of surgery refers to the time relationship of surgery with the systemic treatment period (mainly the duration of systemic chemotherapy), including surgery before chemotherapy (SBC), surgery during chemotherapy (SDC) and surgery after chemotherapy (SAC). The duration of systemic chemotherapy was designed to be an average of 4.6 months (six courses), which was based on the treatment experience of two Chinese tertiary hospitals ${ }^{[19]}$.

\section{Statistical analysis}

The primary analysis of OS was conducted on 153 patients (118 died) at the data-cutoff date of December 31, 2017. Descriptive statistics were used to examine the following baseline characteristics of the breast cancer patients: age, year of diagnosis, tumor size, regional node status, tumor grade, molecular subtype, types of surgery, and radiation. Continuous variables were reported as mean \pm standard deviation and compared by Mann-Whitney $U$ test between the LRT and STA groups because normality was not assumed. Categorical variables were analyzed by chi-square test or Fisher's exact test if expected value $\leq 5$ was found. The statistical significance level for all the tests was set at a 2-tailed value of $p<0.05$. Univariate and multivariate Cox regression models were used to investigate the associations between independent variables and OS. Kaplan-Meier survival analysis and log-rank test were used to estimate and compare the OS with respect to associated factors. The hazard ratio for death in the analysis of OS was estimated with the use of a stratified Cox proportional-hazards model. Analyses were performed in the following subgroups: patients receiving surgery therapy, timing of the surgery, surgical margin and patients receiving radiation therapy. An additional exploratory analysis was carried out to assess the consistency of survival benefit in subgroups based on clinicopathologic characteristics. All analyses were conducted with Stata 16.0 (Stata Corp LP).

\section{Results}

\section{Patients and treatment}

From March 2007 through December 2017, a total of 153 female patients met the study criteria and were included in the analysis. The median age at diagnosis was 55.8 years ( $26-82$ years). The median followup time was 33 months (range 5-128 months). Demographics and baseline characteristics of patients in LRT and STA groups are shown and compared in Table 1. The clinicopathological characteristics of patients undergoing surgery are indicated in Table 2. 
Table 1

Demographics and baseline characteristics

\begin{tabular}{|c|c|c|}
\hline Characteristic & $\begin{array}{l}\text { LRT } \\
n=87 \text {, No. (\%) }\end{array}$ & $\begin{array}{l}\text { STA } \\
n=66, \text { No. (\%) }\end{array}$ \\
\hline \multicolumn{3}{|l|}{ Gender } \\
\hline Female & $87(100)$ & $66(100)$ \\
\hline \multicolumn{3}{|l|}{ Age(yr) } \\
\hline$\leq 50$ & $31(35.6)$ & $22(33.3)$ \\
\hline$>50$ & $56(64.4)$ & $44(66.7)$ \\
\hline \multicolumn{3}{|l|}{ Tumor size(cm) } \\
\hline$\leq 5$ & $54(62.1)$ & $21(31.8)$ \\
\hline$>5$ & $33(37.9)$ & $45(68.2)$ \\
\hline \multicolumn{3}{|l|}{ Nodal status } \\
\hline NO & $20(23.0)$ & 11(16.7) \\
\hline $\mathrm{N} 1$ & $23(26.4)$ & $16(24.2)$ \\
\hline N2 & $28(32.2)$ & $24(36.4)$ \\
\hline N3 & 16(18.4) & $15(22.7)$ \\
\hline \multicolumn{3}{|l|}{ Ki-67 index Ж } \\
\hline$\leq 20 \%$ & 26(29.9) & $12(18.2)$ \\
\hline$>20 \%$ & $52(59.8)$ & $42(63.6)$ \\
\hline unknown & $9(10.3)$ & $12(18.2)$ \\
\hline \multicolumn{3}{|l|}{ Metastatic sites } \\
\hline Bone only & $43(49.4)$ & $12(18.2)$ \\
\hline Viscera only & 28(32.2) & $24(36.4)$ \\
\hline Multi-organ metastasis & $16(18.4)$ & $30(45.4)$ \\
\hline
\end{tabular}

Abbreviations: LRT, locoregional therapy; STA, systematic therapy alone; yr,year; HR, hormone receptor; HER-2, human epidermal growth factor receptor-2. The asteriskЖ indicates that the Ki-67 threshold is set to $20 \%$ instead of $14 \%$. 


\begin{tabular}{|c|c|c|}
\hline \multirow[t]{2}{*}{ Characteristic } & LRT & STA \\
\hline & $\mathrm{n}=87$, No. $(\%)$ & $\mathrm{n}=66$, No. $(\%)$ \\
\hline \multicolumn{3}{|c|}{ Molecular subtypes } \\
\hline Luminal A & $21(24.1)$ & $10(15.1)$ \\
\hline Luminal B & $38(43.7)$ & $36(54.5)$ \\
\hline Her-2 positive & $17(19.5)$ & $12(18.2)$ \\
\hline Triple negative & $9(10.3)$ & $4(6.1)$ \\
\hline Unknown & $2(3.4)$ & $4(6.1)$ \\
\hline \multicolumn{3}{|l|}{ HR status } \\
\hline Negative & $31(35.6)$ & $20(30.3)$ \\
\hline Positive & $56(64.4)$ & $46(69.7)$ \\
\hline \multicolumn{3}{|c|}{ HER-2 expression } \\
\hline Negative & $47(54.0)$ & $26(39.4)$ \\
\hline Positive & $27(31.0)$ & $24(36.4)$ \\
\hline Unknown & $13(15.0)$ & $16(24.2)$ \\
\hline \multicolumn{3}{|c|}{$\begin{array}{l}\text { Abbreviations: LRT, locoregional therapy; STA, systematic therapy alone; yryear; HR, hormone receptor } \\
\text { HER-2, human epidermal growth factor receptor- } 2 \text {. The asteriskЖ indicates that the Ki- } 67 \text { threshold is } \\
\text { set to } 20 \% \text { instead of } 14 \% \text {. }\end{array}$} \\
\hline
\end{tabular}


Table 2

Clinicopathological characteristics of patients undergoing surgery

\begin{tabular}{|c|c|c|c|}
\hline \multirow[t]{2}{*}{ Characteristics } & \multirow[b]{2}{*}{ SAC } & \multirow{2}{*}{$\begin{array}{l}\text { Surgery }(n=78) \\
\text { SBC }\end{array}$} & \multirow[t]{2}{*}{ SDC } \\
\hline & & & \\
\hline \multicolumn{4}{|l|}{ Age(yr) } \\
\hline$\leq 50$ & 11 & 9 & 9 \\
\hline$>50$ & 19 & 17 & 13 \\
\hline \multicolumn{4}{|l|}{ Tumor size(cm) } \\
\hline$\leq 5$ & 17 & 17 & 15 \\
\hline$>5$ & 13 & 9 & 7 \\
\hline \multicolumn{4}{|l|}{ Ki-67 index $\square$} \\
\hline$\leq 20 \%$ & 11 & 4 & 6 \\
\hline$>20 \%$ & 18 & 19 & 12 \\
\hline Unknown & 1 & 3 & 4 \\
\hline \multicolumn{4}{|l|}{ Metastatic sites } \\
\hline Bone only & 21 & 12 & 9 \\
\hline Viscera only & 6 & 8 & 11 \\
\hline Multi-organ metastasis & 3 & 6 & 2 \\
\hline \multicolumn{4}{|l|}{ Molecular subtypes } \\
\hline Luminal A & 7 & 4 & 9 \\
\hline Luminal B & 13 & 13 & 7 \\
\hline Her-2 positive & 5 & 6 & 4 \\
\hline Triple negative & 4 & 2 & 1 \\
\hline Unknown & 1 & 1 & 1 \\
\hline \multicolumn{4}{|l|}{ HR status } \\
\hline Negative & 10 & 9 & 9 \\
\hline Positive & 20 & 17 & 13 \\
\hline
\end{tabular}

Abbreviations: SAC, surgery after chemotherapy; SBC, surgery before chemotherapy; SDC, surgery during chemotherapy; HR, hormone receptor; HER-2, human epidermal growth factor receptor-2; yr,year; (Ж) indicates that the Ki-67 threshold is set to $20 \%$ instead of $14 \%$. 
Characteristics

Surgery $(n=78)$

SDC

SAC SBC

HER-2 expression

Negative

19

13

10

Positive

5

10

9

Unknown

6

3

3

\section{Type of surgery}

$\begin{array}{llll}\text { Mastectomy } & 2 & 3 & 6 \\ \text { Lumpectomy } & 28 & 23 & 16\end{array}$

\section{Surgical margins}

Negative

20

16

14

Positive

Unknown

3

1

2

Abbreviations: SAC, surgery after chemotherapy; SBC, surgery before chemotherapy; SDC, surgery during chemotherapy; HR, hormone receptor; HER-2, human epidermal growth factor receptor-2; yr,year; (Ж) indicates that the Ki-67 threshold is set to $20 \%$ instead of $14 \%$.

\section{Kaplan-meier survival estimate}

At the data cutoff date for the analysis of OS (Dec 31, 2017), 118 deaths had occurred: 64 among 87 patients (73.6\%) in LRT group and 54 among 66 patients (81.8\%) in STA group. OS was significantly improved in LRT group versus STA group, with a median OS of 42 months ( $95 \% \mathrm{Cl}, 35.0$ to 48.9 months) versus 21 months ( $95 \% \mathrm{Cl}, 16.1$ to 25.9 months), respectively. A significant OS benefit was noted in LRT group as compared with STA group, with a $53 \%$ difference in the relative risk of death $(\mathrm{HR}, 0.47 ; 95 \% \mathrm{Cl}$, 0.33 to $0.69 ; P<.0001$; Fig. 1.).

\section{Stratified analyses associated with OS}

Subgroup analyses that were defined according to clinicopathological characteristics and treatment options were performed. Obviously, the benefits of surgery with respect to OS in the present study are noteworthy in the context of locoregional therapy for patients with dnMBC. OS calculated via the KaplanMeier method showed a significant difference between the surgery and the non-surgery group (HR, 0.48 ; $95 \% \mathrm{Cl}, 0.33$ to $0.70 ; \mathrm{Fig}$. 2.). The equality of these curves was confirmed by log-rank rest $(P=.0001)$. The median OS was 42 months ( $95 \% \mathrm{Cl}, 34.1$ to 49.9 months) in patients who had surgery and 22 months $(95 \% \mathrm{Cl}, 17.8$ to 26.2 months) in patients who had non-surgery. 
For surgical patients, the median OS was 56 months ( $95 \% \mathrm{Cl}, 40.8$ to 71.2$)$ in patients who underwent SAC and 35 months $(95 \% \mathrm{Cl}, 24.3$ to 45.7$)$ in patients who underwent SBC; and the median OS of patients receiving SDC was 43 months $(\mathrm{Cl}, 18.6$ to 67.4$)$, which was higher than that of all patients receiving surgical treatment. OS calculated via the Kaplan-Meier method showed a significant difference between the three arms (HR, $0.79 ; 95 \% \mathrm{Cl}, 0.65$ to $0.95 ; \mathrm{P}=.013$ Fig. 3.).

Of the 78 patients received primary tumor surgery, 67 (85.9\%) had lumpectomy and $11(14.1 \%)$ had mastectomy. The surgical margins status of primary breast cancer was found to be an affecting factor on OS for patients who had surgery. As shown in Fig. 4, OS was significantly improved in patients with negative margins versus patients with positive margins, with a median OS of 56 months $(95 \% \mathrm{Cl}, 45.9$ to 66.1 months) versus 16 months ( $95 \% \mathrm{Cl}, 10.3$ to 21.7 months), respectively, and a hazard ratio of 2.35 $(95 \% \mathrm{Cl}, 1.65$ to $3.35 ; \mathrm{P}<.0001)$.

As an alternative to surgery, the effects of radiotherapy on OS were also subgroup analyzed in the present study. The results were received for radiotherapy on survival with a $p$ value of 0.053 calculated by logrank statistics. The OS in this subgroup was 47 months versus 37 months $(\mathrm{HR}, 0.65 ; 95 \% \mathrm{Cl}, 0.43$ to 1.01 ; Fig. 5.). Of the total cohort, the majority receiving no radiotherapy and only 38 cases (nine patients received radiotherapy alone) being analyzed (a small sample size and limited number of events), thus the treatment effect hazard ratio in the subgroup of patients should be interpreted with caution.

As shown in Fig. 6, exploratory analyses demonstrated consistent treatment effects across specified subgroups. The results for OS in subgroups were generally consistent with those in the overall population.

\section{Discussion}

The retrospective cohort study demonstrated that LRT was associated with a significant benefit with respect to OS with a 53\% relative difference in the risk of death as compared STA in women with dnMBC. Subgroup analyses also demonstrated improved outcomes in patients who had received surgery in these patients, with a median OS of 42 months (HR, 0.48), compared with no-surgery. Herein, we found that LRT, the combinations of surgery with radiation therapy used in this patient population have shown a consistent and meaningful prolongation of survival over STA. The Kaplan-Meier curve for OS showed separation between the two groups beginning at approximately 10 months, and the separation widened over time. This OS benefit was generally consistent across patient subgroups, including those who received surgical resection of the primary tumor. In this study, the greatest benefits were seen among both patients who had surgery with negative margins and patients undergone SAC or SDC, with an average survival of 56 months, regardless of the site of their metastatic disease. Exploratory analyses also demonstrated consistent treatment effects across specified subgroups. Our findings show that LRT in patients with dnMBC had a positive impact on OS. This work will support and add evidence to the critical concepts in the treatment of women with dnMBC. 
With respect to the survival effects of $L R T$ in patients with dnMBC, retrospective studies have shown the potential survival benefits ${ }^{[8,15,39-45]}$, while prospective studies have revealed mixed results ${ }^{[29]}$. Currently, three published prospective studies have assessed the impact of LRT in dnMBC. A randomized controlled trial by Badwe et al. ${ }^{[35]}$ found no difference in OS based on LRT; another study by Soran et al. ${ }^{[36]}$ randomized $274 \mathrm{dnMBC}$ patients to either LRT or SAT, in whom survival was similar at 36 months, but actually higher in LRT group vs STA group at 60 months; the ABCSG-28 POSYTIVE trial by Fitzal F et al. ${ }^{[37]}$ stopped early owing to poor recruitment and no definite conclusion was reached. In addition, a prospective registry study of 127 patients noted no improvement in OS for those having resection of their intact primary disease. To date, prospective trials failed to provide a definitive answer to the question of optimal utility of surgery in this patient population ${ }^{[46]}$. Despite these trials have been criticized due to systemic therapy protocols which differ from standard modern treatments, as well as broad inclusion and exclusion criteria, they continue to provide important data. By contrast, multiple retrospective studies and large meta-analysis have revealed the potential survival benefits with LRT in patients with dnMBC. A recent meta-analysis by Ritika Gera et al., of 216066 patients found all forms of LRT resulted in a significant $31.8 \%$ reduction in mortality and surgical resection resulted in a significant $36.2 \%$ reduction in mortality. Ritika Gera therefore concluded that LRT of the primary tumour seems to improve overall survival in dnMBC ${ }^{[21]}$. Another study by Seo et al. showed that LRT might be an important option for dnMBC patients ${ }^{[47]}$. Our findings are in accordance with these reports analyzing the impact of LRT on survival.

The latest research from the NCDB (2003-2012) demonstrated that among women alive 1 year after a diagnosis of metastatic breast cancer, surgical resection of the primary tumor was associated with improved survival, regardless of treatment sequence ${ }^{[8]}$. Another recent study based on the SEER database (2010-2015) proposed a survival advantage with surgical intervention (median OS, 43 months for surgery vs. 27 months for non-surgery) ${ }^{[45]}$. Similarly, in our study, the median OS of the two groups was 42 months vs. 22 months, respectively.

Most retrospective studies focused on the survival outcomes of surgical treatment after systemic chemotherapy. For example, a recent research by Whitney 0 . Lane et al. from NCDB showed that the greatest survival benefit was seen in women treated with systemic therapy followed by surgery; median OS was 52.8 months compared to 37.5 months for those undergoing STA ${ }^{[8]}$. However, no studies discussed the survival of receiving surgical treatment at three different time periods (SAC, SDC and SBC) in dnMBC patients. One of major strength of this study, we analyzed the survival outcomes of SBC, SDC and SAC, rather than that of SAC alone.

In the present study, despite defferent timings of surgery that included SAC, SDC and SBC, patients underwent resection of the primary tumor not only failed to increase the risk of death, but instead showed an improvement in OS compared to nonsurgical treatment during the follow-up period. Moreover, our study found a significant OS difference between patients in whom the three surgical options were SAC, SDC and SBC. Compared with SBC, both SAC and SDC have a survival advantage in these three different 
options $(p=0.013)$. The authors speculated that patients with SAC or SDC may have an opportunity to receive preoperative or concurrent chemotherapy with surgery, and thus respond well to complete local remission of the tumor, leading to prolonged survival.

We also found that surgery with negative margin had a positive impact on OS for surgical patients. In our study, OS was significantly improved in patients with negative margins versus patients with positive margins, with a median OS of 56 months versus 16 months $(p<.0001)$, respectively. The results of this study show that the surgical removal of primary tumor in these patients does not impair survival but actually improves prognosis if done with negative surgical margins. It has been suggested that the total tumor burden plays a central role in survival and that the removal of the primary tumour reduces the tumour burden, thereby increasing response to systemic therapy ${ }^{[44,48]}$. Another factor is that the primary tumour is that the main source of new clonal lines of cancer cells, which are implicated in the emergence of resistance to therapy and the appearance of more aggressive disease phenotypes ${ }^{[49]}$. Consistent with this hypothesis, recent studies found a strong correlation between the level of circulating tumor cells and prognosis of metastatic breast cancer ${ }^{[50,51]}$. Surgery would disrupt this process.

As an alternative to surgery, the survival impact of radiotherapy were also analyzed in the present study. The results were received for radiotherapy on survival with a $p$ value of 0.053 calculated by log-rank statistics (47 months versus 37 months). Obviously, our findings are not consistent with the conclusions of contemporaneous cohorts from the literature ${ }^{[4,52-55]}$. Current trial showed that those patients who received radiation did not improve their survival, possibly because of the small sample and size limited number of events.

Some limitations in the interpretation of our findings should be acknowledged. This study's retrospective nature inevitably leads to certain limitations, such as potential selection bias, and the reliance on various clinicians' documentation of indications for treatments. For patients, the choice of treatment is usually at the clinicians' discretion. Moreover, the study includes a limited number of patients and it is not possible to derive definitive conclusions regarding survival outcomes, especially relative to LRT. Despite these limitations, our study has several strengths. We tried to address some controversial and important issues in a field where limited data are available. First, few studies have compared the survival outcomes of dnMBC patients undergoing surgery at three different intervals between systemic chemotherapy and surgery. To the best of our knowledge, this is the first study that assessed the survival outcomes of these patients with a particular focus on the three different intervals associated with use of surgery, and concluded that SAC and SDC benefited significantly. Furthermore, whether surgical margins corresponding to the three surgical procedures have an impact on patient survival has not been previously studied. In the present study, we found a significant survival difference between patients in whom the surgical margins were negative and positive. The results showed that patient who had SAC or SDC, with negative surgical margins, were expected to have better survival. However, due to the above limitations, in our study, more researches should be conducted to confirm the hypothesis. 


\section{Conclusions}

The current study demonstrates that LRT significantly improves survival in patients with dnMBC compared to STA. The benefits of surgery with respect to OS in our study are noteworthy in the context of LRT in this patient population, especially in patients undergoing surgery after or during chemotherapy with negative margins. This study provides additional evidence that LRT may have survival benefit in this patient population. While waiting for the result of ECOG 2108 trial, well-designed prospective studies are needed to re-evaluate LRT strategy for patients with dnMBC.

\section{List Of Abbreviations}

OS,overall survival; dnMBC,de novo metastatic breast cancer; LRT,locoregional treatment; STA,systemic therapy alone; RT,radiation therapy; No RT,non-radiotherapy; SBC,surgery before chemotherapy; SDC,surgery during chemotherapy; SAC,surgery after chemotherapy; $\mathrm{HR}$, hazard ratio; $\mathrm{Cl}$, confidence intervals; ESMO, European Society for Medical Oncology; NCCN, National Comprehensive Cancer Network.

\section{Declarations}

\section{Acknowledgements}

We would like to acknowledge the Department of breast oncology, Tianjin medical university cancer institute and hospital, Tianjin medical university.

\section{Availability of data and materials}

The datasets used and analyzed during the current study are stored in corresponding author of this paper and are available upon request.

\section{Ethics approval and consent to participate}

Approval for this study was obtained from the local clinical research ethics committees (NO. 2017-AF29058).

\section{Patient consent for publication}

No written consent was required for the publication of data because this study is retrospective.

\section{Funding}

No funding was received. 
The authors have no conflict of interest or financial disclosure to declare.

\section{Author's contribution to the manuscript}

SJ and KL conceived of the study, and participated in its design and coordination and drafted the manuscript. FN carried out data collection and analysis. LH participated in the design of the study and made critical revision of the article; RC participated in its design and coordination and helped to draft the manuscript. All authors read and approved the final manuscript.

\section{References}

1. Siegel RL, Miller KD, Jemal A. Cancer statistics, 2018. CA: a cancer journal for clinicians. 2018;68(1):7-30.

2. Jimeno A, Amador ML, González-Cortijo L, Tornamira MV, Ropero S, Valentín V, et al. Initially metastatic breast carcinoma has a distinct disease pattern but an equivalent outcome compared with recurrent metastatic breast carcinoma. Cancer. 2004;100(9):1833-42.

3. Chang J, Clark GM, Allred DC, Mohsin S, Chamness G, Elledge RM. Survival of patients with metastatic breast carcinoma: importance of prognostic markers of the primary tumor. Cancer. 2003;97(3):545-53.

4. Pons-Tostivint E, Kirova Y, Lusque A, Campone M, Geffrelot J, Rivera S, et al. Radiation therapy to the primary tumor for de novo metastatic breast cancer and overall survival in a retrospective multicenter cohort analysis. Radiother Oncol. 2020;145:109-16.

5. Si Y, Yuan P, Hu N, Wang X, Ju J, Wang J, et al. Primary Tumor Surgery for Patients with De Novo Stage IV Breast Cancer can Decrease Local Symptoms and Improve Quality of Life. Ann Surg Oncol. 2020;27(4):1025-33.

6. Cardoso F, Costa A, Norton L, Senkus E, Aapro M, André F, et al. ESO-ESMO 2nd international consensus guidelines for advanced breast cancer (ABC2). Breast (Edinburgh, Scotland). 2014;23(5):489-502.

7. Slamon DJ, Neven P, Chia S, Fasching PA, De Laurentiis M, Im SA, et al. Overall Survival with Ribociclib plus Fulvestrant in Advanced Breast Cancer. N Engl J Med. 2020;382(6):514-24.

8. Lane WO, Thomas SM, Blitzblau RC, Plichta JK, Rosenberger LH, Fayanju OM, et al. Surgical Resection of the Primary Tumor in Women With De Novo Stage IV Breast Cancer: Contemporary Practice Patterns and Survival Analysis. Annals of surgery. 2019;269(3):537-44.

9. Tevaarwerk AJ, Gray RJ, Schneider BP, Smith ML, Wagner LI, Fetting JH, et al. Survival in patients with metastatic recurrent breast cancer after adjuvant chemotherapy: little evidence of improvement over the past 30 years. Cancer. 2013;119(6):1140-8.

10. Sledge GW, Jr. Curing Metastatic Breast Cancer. J Oncol Pract. 2016;12(1):6-10.

11. Johnson N, Pellino G, Simillis C, Qiu S, Nikolaou S, Baird DL, et al. Discrepancies between NCCN and ESMO guidelines in the management of anal cancer: a qualitative review. Updates Surg. 
2017;69(3):345-9.

12. Gradishar WJ, Anderson BO, Abraham J, Aft R, Agnese D, Allison KH, et al. Breast Cancer, Version 3.2020, NCCN Clinical Practice Guidelines in Oncology. Journal of the National Comprehensive Cancer Network : JNCCN. 2020;18(4):452-78.

13. Cardoso F, Senkus E, Costa A, Papadopoulos E, Aapro M, André F, et al. 4th ESO-ESMO International Consensus Guidelines for Advanced Breast Cancer (ABC 4)t. Annals of oncology : official journal of the European Society for Medical Oncology. 2018;29(8):1634-57.

14. Soran A. Are we close to the end of the primary tumor resection discussion for de novo stage IV BC? European journal of surgical oncology : the journal of the European Society of Surgical Oncology and the British Association of Surgical Oncology. 2019;45(2):81-2.

15. Thomas A, Khan SA, Chrischilles EA, Schroeder MC. Initial Surgery and Survival in Stage IV Breast Cancer in the United States, 1988-2011. JAMA surgery. 2016;151(5):424-31.

16. Warschkow R, Güller U, Tarantino I, Cerny T, Schmied BM, Thuerlimann B, et al. Improved Survival After Primary Tumor Surgery in Metastatic Breast Cancer: A Propensity-adjusted, Population-based SEER Trend Analysis. Annals of surgery. 2016;263(6):1188-98.

17. Lopez-Tarruella S, Escudero MJ, Pollan M, Martin M, Jara C, Bermejo B, et al. Survival impact of primary tumor resection in de novo metastatic breast cancer patients (GEICAM/El Alamo Registry). Scientific reports. 2019;9(1):20081.

18. Lang JE, Tereffe W, Mitchell MP, Rao R, Feng L, Meric-Bernstam F, et al. Primary tumor extirpation in breast cancer patients who present with stage IV disease is associated with improved survival. Annals of surgical oncology. 2013;20(6):1893-9.

19. Ren CX, Sun JN, Kong LJ, Liu H. Local therapy and its association on survival outcomes in patients with de novo stage IV breast cancer: Results from a retrospective cohort study. Cancer research. 2020;80(4).

20. Xiong Z, Deng G, Wang J, Li X, Xie X, Shuang Z, et al. Could local surgery improve survival in de novo stage IV breast cancer? BMC cancer. 2018;18(1):885.

21. Gera R, Chehade H, Wazir U, Tayeh S, Kasem A, Mokbel K. Locoregional therapy of the primary tumour in de novo stage IV breast cancer in 216066 patients: A meta-analysis. Scientific reports. 2020;10(1):2952.

22. Shibasaki S, Jotoku H, Watanabe K, Takahashi M. Does primary tumor resection improve outcomes for patients with incurable advanced breast cancer? Breast (Edinburgh, Scotland). 2011;20(6):543-7.

23. Rosche M, Regierer AC, Schwarzlose-Schwarck S, Weigel A, Bangemann N, Schefe JH, et al. Primary tumor excision in stage IV breast cancer at diagnosis without influence on survival: a retrospective analysis and review of the literature. Onkologie. 2011;34(11):607-12.

24. Dominici L, Najita J, Hughes M, Niland J, Marcom P, Wong YN, et al. Surgery of the primary tumor does not improve survival in stage IV breast cancer. Breast cancer research and treatment. 2011;129(2):459-65. 
25. Khan SA. Surgical Management of de novo Stage IV Breast Cancer. Semin Radiat Oncol. 2016;26(1):79-86.

26. Tosello G, Torloni MR, Mota BS, Neeman T, Riera R. Breast surgery for metastatic breast cancer. The Cochrane database of systematic reviews. 2018;3:Cd011276.

27. Sun JN, Kong LJ, Ren CX, Liu H. Clinicopathological features and treatment outcomes in patients with initially diagnosed stage IV breast cancer bone metastasis. International Journal of Clinical and Experimental Medicine. 2019;12(9):11645-56.

28. Rashaan ZM, Bastiaannet E, Portielje JE, van de Water W, van der Velde S, Ernst MF, et al. Surgery in metastatic breast cancer: patients with a favorable profile seem to have the most benefit from surgery. European journal of surgical oncology : the journal of the European Society of Surgical Oncology and the British Association of Surgical Oncology. 2012;38(1):52-6.

29. Arciero C, Liu Y, Gillespie T, Subhedar P. Surgery and survival in patients with stage IV breast cancer. Breast J. 2019;25(4):644-53.

30. Rhu J, Lee SK, Kil WH, Lee JE, Nam SJ. Surgery of primary tumour has survival benefit in metastatic breast cancer with single-organ metastasis, especially bone. ANZ J Surg. 2015;85(4):240-4.

31. Xiao WK, Zou YT, Zheng SQ, Hu XQ, Liu P, Xie XH, et al. Primary tumor resection in stage IV breast cancer: A systematic review and meta-analysis. Ejso. 2018;44(10):1504-12.

32. Headon $\mathrm{H}$, Wazir $\mathrm{U}$, Kasem A, Mokbel K. Surgical treatment of the primary tumour improves the overall survival in patients with metastatic breast cancer: A systematic review and meta-analysis. Molecular and clinical oncology. 2016;4(5):863-7.

33. Petrelli F, Barni S. Surgery of primary tumors in stage IV breast cancer: an updated meta-analysis of published studies with meta-regression. Medical oncology (Northwood, London, England). 2012;29(5):3282-90.

34. Harris E, Barry M, Kell MR. Meta-analysis to determine if surgical resection of the primary tumour in the setting of stage IV breast cancer impacts on survival. Annals of surgical oncology. 2013;20(9):2828-34.

35. Badwe R, Hawaldar R, Nair N, Kaushik R, Parmar V, Siddique S, et al. Locoregional treatment versus no treatment of the primary tumour in metastatic breast cancer: an open-label randomised controlled trial. The Lancet Oncology. 2015;16(13):1380-8.

36. Soran A, Ozmen V, Ozbas S, Karanlik H, Muslumanoglu M, Igci A, et al. Randomized Trial Comparing Resection of Primary Tumor with No Surgery in Stage IV Breast Cancer at Presentation: Protocol MF07-01. Annals of surgical oncology. 2018;25(11):3141-9.

37. Fitzal F, Bjelic-Radisic V, Knauer M, Steger G, Hubalek M, Balic M, et al. Impact of Breast Surgery in Primary Metastasized Breast Cancer: Outcomes of the Prospective Randomized Phase III ABCSG-28 POSYTIVE Trial. Annals of surgery. 2019;269(6):1163-9.

38. Khan SA, DesJardin ESM. Readdressing the Role of Surgery of the Primary Tumor in de Novo Stage IV Breast Cancer. In: Gradishar WJ, editor. Optimizing Breast Cancer Management. Cancer Treatment and Research. 1732018. p. 73-88. 
39. Desille-Gbaguidi H, Avigdor S, Body G, Ouldamer L. Survival impact of primary site surgery on metastatic breast cancer patients at diagnosis. Journal of gynecology obstetrics and human reproduction. 2019;48(3):171-7.

40. Pathy NB, Verkooijen HM, Taib NA, Hartman M, Yip CH. Impact of breast surgery on survival in women presenting with metastatic breast cancer. Br J Surg. 2011;98(11):1566-72.

41. Ruiterkamp J, Ernst MF, van de Poll-Franse LV, Bosscha K, Tjan-Heijnen VC, Voogd AC. Surgical resection of the primary tumour is associated with improved survival in patients with distant metastatic breast cancer at diagnosis. European journal of surgical oncology : the journal of the European Society of Surgical Oncology and the British Association of Surgical Oncology. 2009;35(11):1146-51.

42. Rapiti E, Verkooijen HM, Vlastos G, Fioretta G, Neyroud-Caspar I, Sappino AP, et al. Complete excision of primary breast tumor improves survival of patients with metastatic breast cancer at diagnosis. Journal of clinical oncology : official journal of the American Society of Clinical Oncology. 2006;24(18):2743-9.

43. Gnerlich J, Jeffe DB, Deshpande AD, Beers C, Zander C, Margenthaler JA. Surgical removal of the primary tumor increases overall survival in patients with metastatic breast cancer: analysis of the 1988-2003 SEER data. Annals of surgical oncology. 2007;14(8):2187-94.

44. Khan SA, Stewart AK, Morrow M. Does aggressive local therapy improve survival in metastatic breast cancer? Surgery. 2002;132(4):620-6; discussion 6-7.

45. Lin Y, Huang K, Zeng Q, Zhang J, Song C. Impact of breast surgery on survival of patients with stage IV breast cancer: a SEER population-based propensity score matching analysis. PeerJ. 2020;8:e8694.

46. King TA, Lyman J, Gonen M, Reyes S, Hwang ESS, Rugo HS, et al. A prospective analysis of surgery and survival in stage IV breast cancer (TBCRC 013). Journal of Clinical Oncology. 2016;34(15).

47. Choi SH, Kim JW, Choi J, Sohn J, Kim SI, Park S, et al. Locoregional Treatment of the Primary Tumor in Patients With De Novo Stage IV Breast Cancer: A Radiation Oncologist's Perspective. Clin Breast Cancer. 2018;18(2):e167-e78.

48. Kim MY, Oskarsson T, Acharyya S, Nguyen DX, Zhang XH, Norton L, et al. Tumor self-seeding by circulating cancer cells. Cell. 2009;139(7):1315-26.

49. Balic M, Lin H, Young L, Hawes D, Giuliano A, McNamara G, et al. Most early disseminated cancer cells detected in bone marrow of breast cancer patients have a putative breast cancer stem cell phenotype. Clin Cancer Res. 2006;12(19):5615-21.

50. Cristofanilli M, Budd GT, Ellis MJ, Stopeck A, Matera J, Miller MC, et al. Circulating tumor cells, disease progression, and survival in metastatic breast cancer. N Engl J Med. 2004;351(8):781-91.

51. Cristofanilli M, Hayes DF, Budd GT, Ellis MJ, Stopeck A, Reuben JM, et al. Circulating tumor cells: a novel prognostic factor for newly diagnosed metastatic breast cancer. Journal of clinical oncology : official journal of the American Society of Clinical Oncology. 2005;23(7):1420-30.

52. Mauro GP, de Andrade Carvalho H, Stuart SR, Mano MS, Marta GN. Effects of locoregional radiotherapy in patients with metastatic breast cancer. Breast (Edinburgh, Scotland). 2016;28:73-8. 
53. Le Scodan R, Stevens D, Brain E, Floiras JL, Cohen-Solal C, De La Lande B, et al. Breast cancer with synchronous metastases: survival impact of exclusive locoregional radiotherapy. Journal of clinical oncology : official journal of the American Society of Clinical Oncology. 2009;27(9):1375-81.

54. Nguyen DH, Truong PT, Alexander C, Walter CV, Hayashi E, Christie J, et al. Can locoregional treatment of the primary tumor improve outcomes for women with stage IV breast cancer at diagnosis? International journal of radiation oncology, biology, physics. 2012;84(1):39-45.

55. Bourgier C, Khodari W, Vataire AL, Pessoa EL, Dunant A, Delaloge S, et al. Breast radiotherapy as part of loco-regional treatments in stage IV breast cancer patients with oligometastatic disease. Radiother Oncol. 2010;96(2):199-203.

\section{Figures}

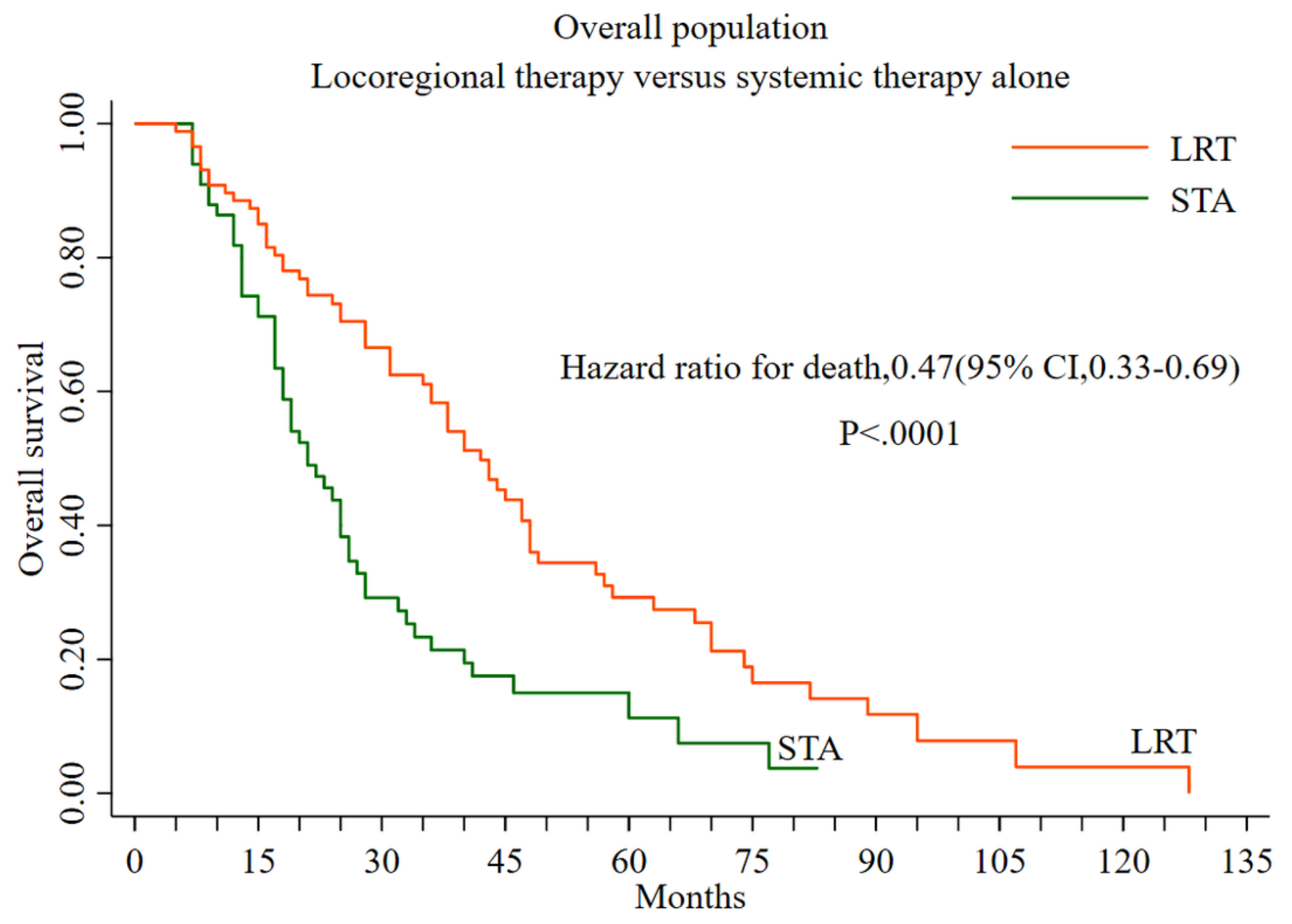

No. at risk

$\begin{array}{ccccccccccc}\text { STA } & 66 & 49 & 16 & 7 & 4 & 2 & 0 & 0 & 0 & 0 \\ \text { LRT } & 87 & 75 & 50 & 30 & 16 & 8 & 5 & 2 & 1 & 0\end{array}$

Figure 1

Overall survival in the overall population according to LRT and STA for de novo metastatic breast cancer. 


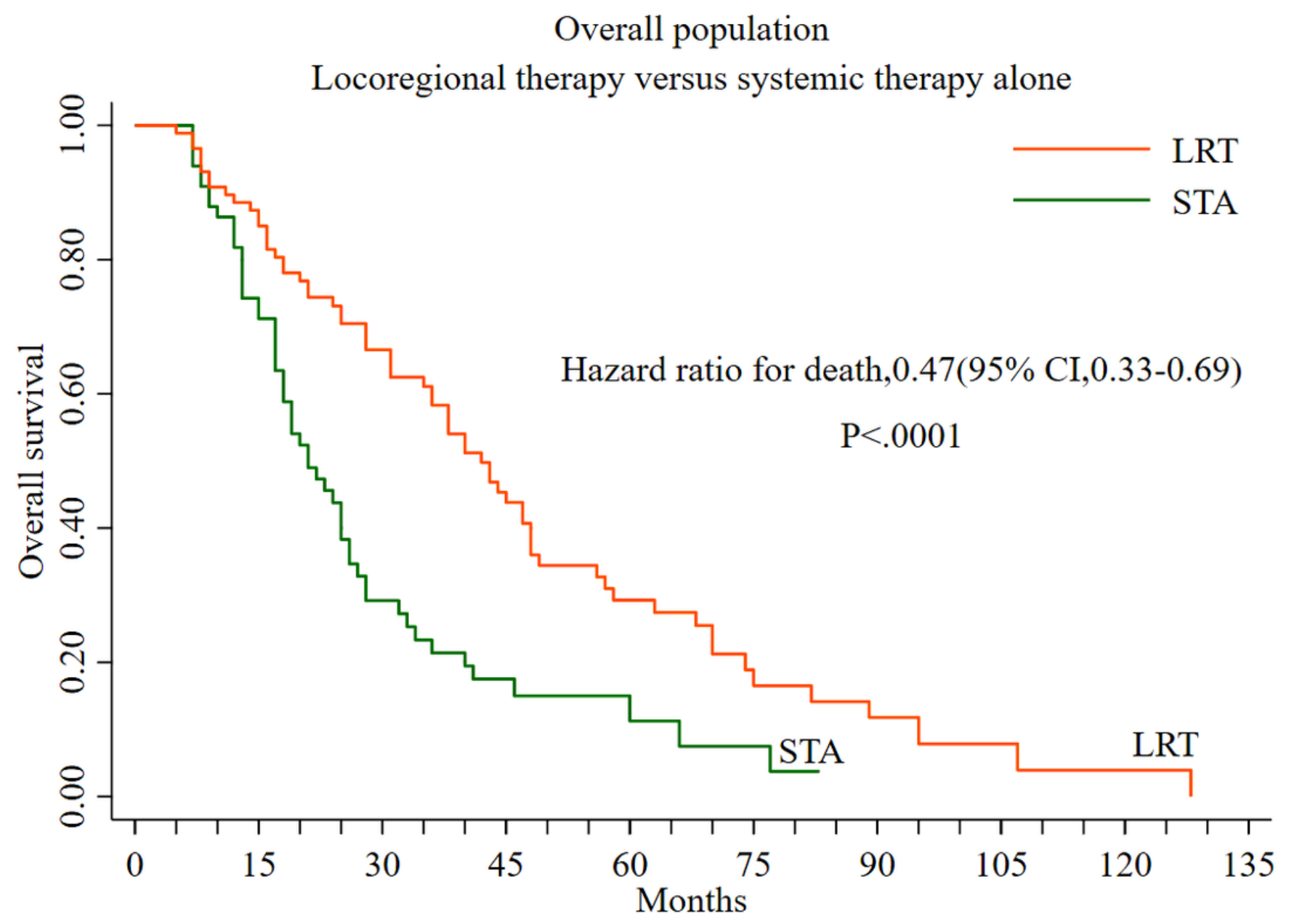

No. at risk

$\begin{array}{ccccccccccc}\text { STA } & 66 & 49 & 16 & 7 & 4 & 2 & 0 & 0 & 0 & 0 \\ \text { LRT } & 87 & 75 & 50 & 30 & 16 & 8 & 5 & 2 & 1 & 0\end{array}$

Figure 1

Overall survival in the overall population according to LRT and STA for de novo metastatic breast cancer. 


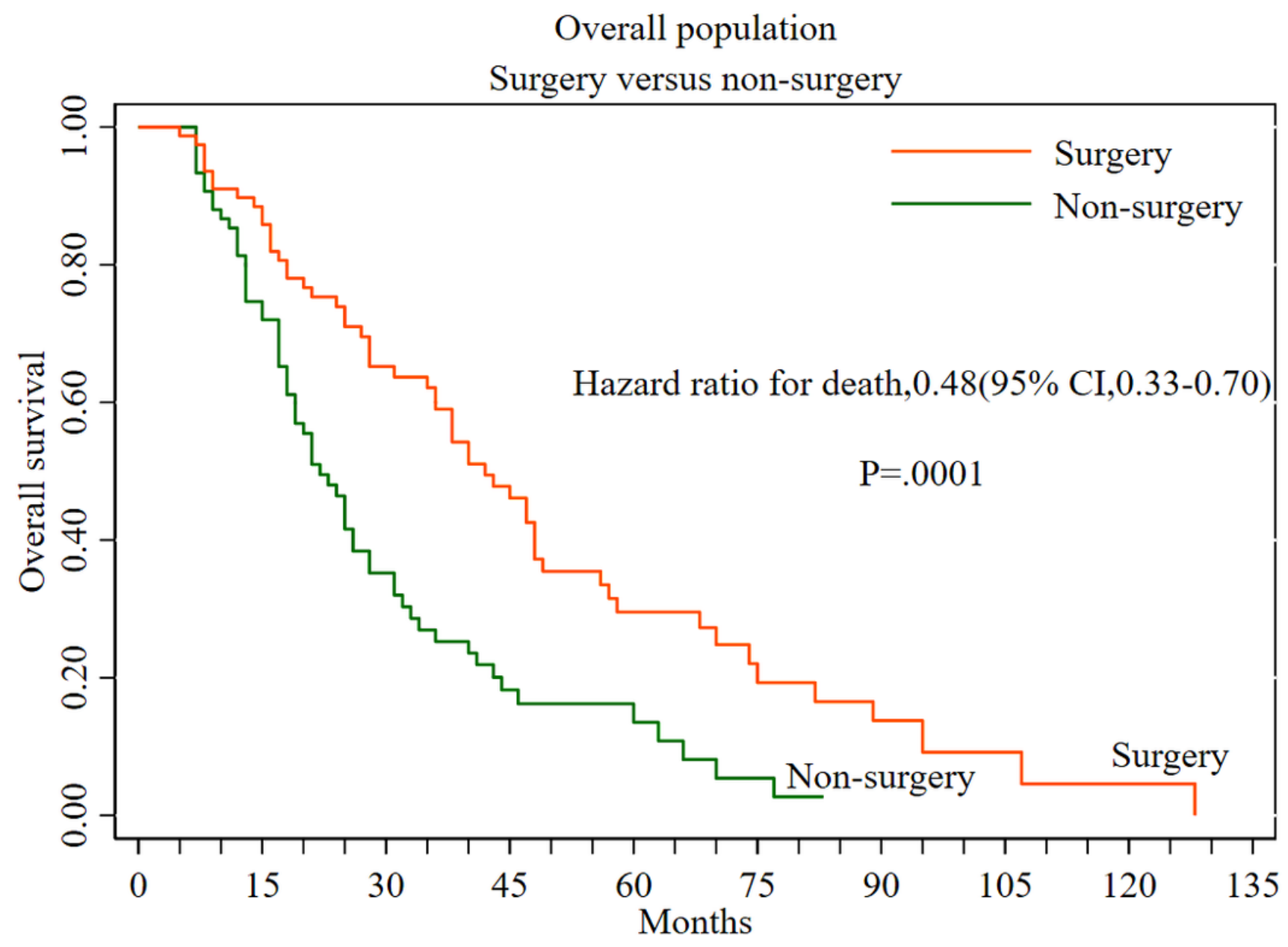

No. at risk

$\begin{array}{rrrrccccccr}\text { Non-surgery } & 75 & 56 & 22 & 9 & 6 & 2 & 0 & 0 & 0 & 0 \\ \text { Surgery } & 78 & 68 & 44 & 28 & 14 & 8 & 5 & 2 & 1 & 0\end{array}$

Figure 2

Overall survival in patients with de novo metastatic breast cancer were assessed to receive either surgery or non-surgery. 


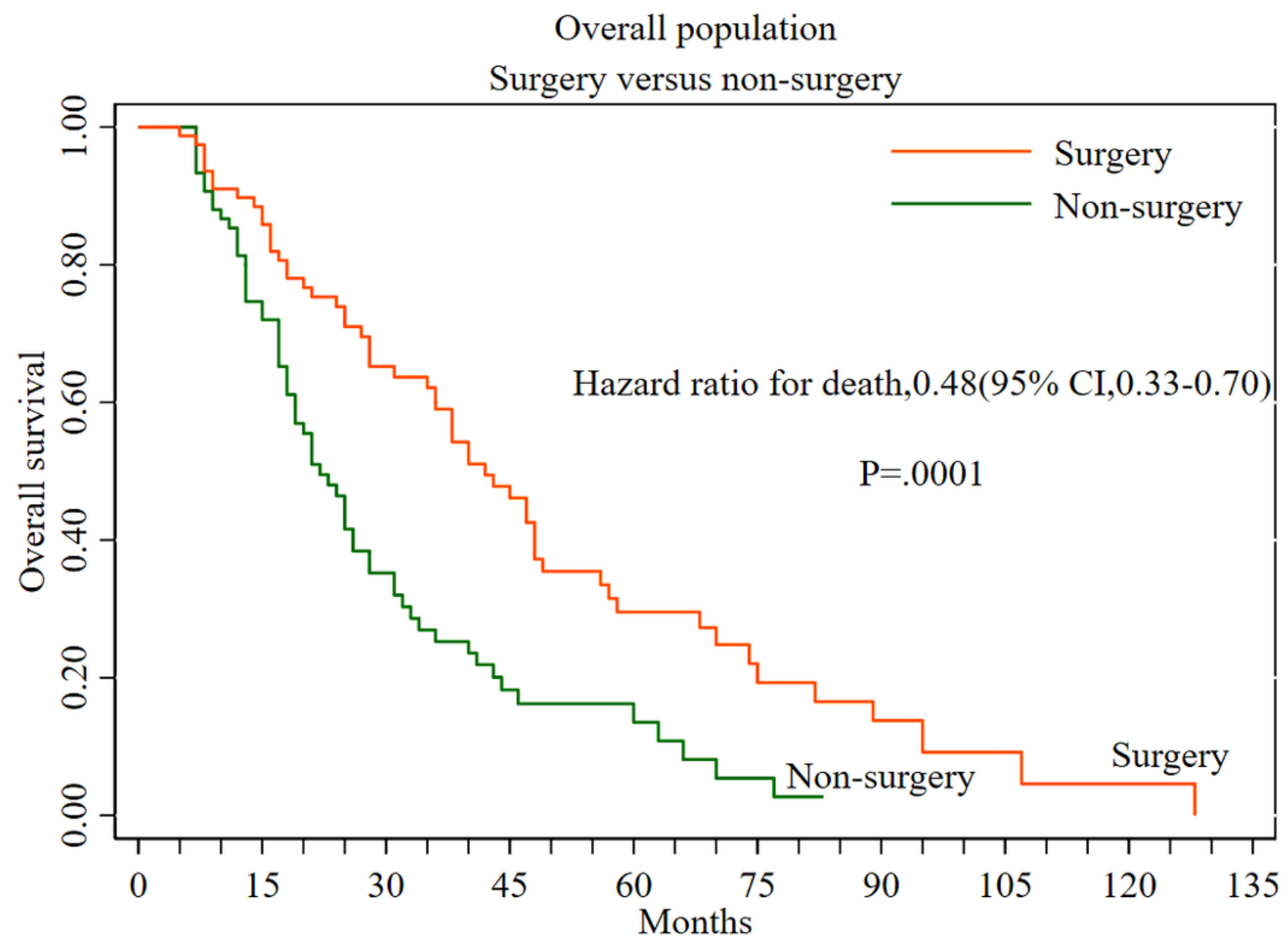

No. at risk

$\begin{array}{rrrrccccccr}\text { Non-surgery } & 75 & 56 & 22 & 9 & 6 & 2 & 0 & 0 & 0 & 0 \\ \text { Surgery } & 78 & 68 & 44 & 28 & 14 & 8 & 5 & 2 & 1 & 0\end{array}$

Figure 2

Overall survival in patients with de novo metastatic breast cancer were assessed to receive either surgery or non-surgery. 


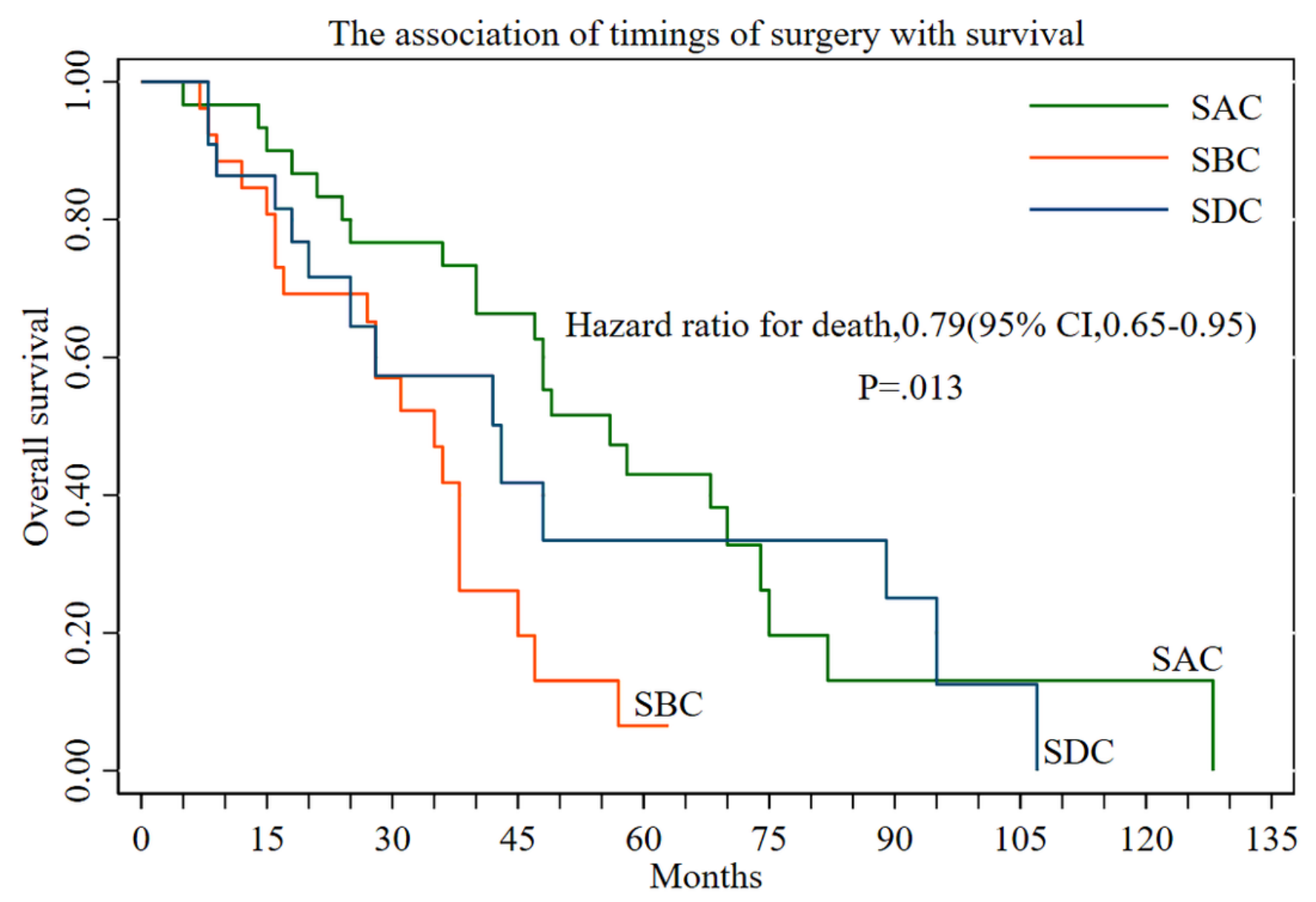

No. at risk

$\begin{array}{ccccccccccc}\text { SAC } & 30 & 28 & 23 & 19 & 9 & 4 & 2 & 1 & 1 & 0 \\ \text { SBC } & 26 & 22 & 13 & 4 & 1 & 0 & 0 & 0 & 0 & 0 \\ \text { SDC } & 22 & 18 & 8 & 5 & 4 & 4 & 3 & 1 & 0 & 0\end{array}$

Figure 3

The association of timings of surgery with survival in patients with de novo metastatic breast cancer. 


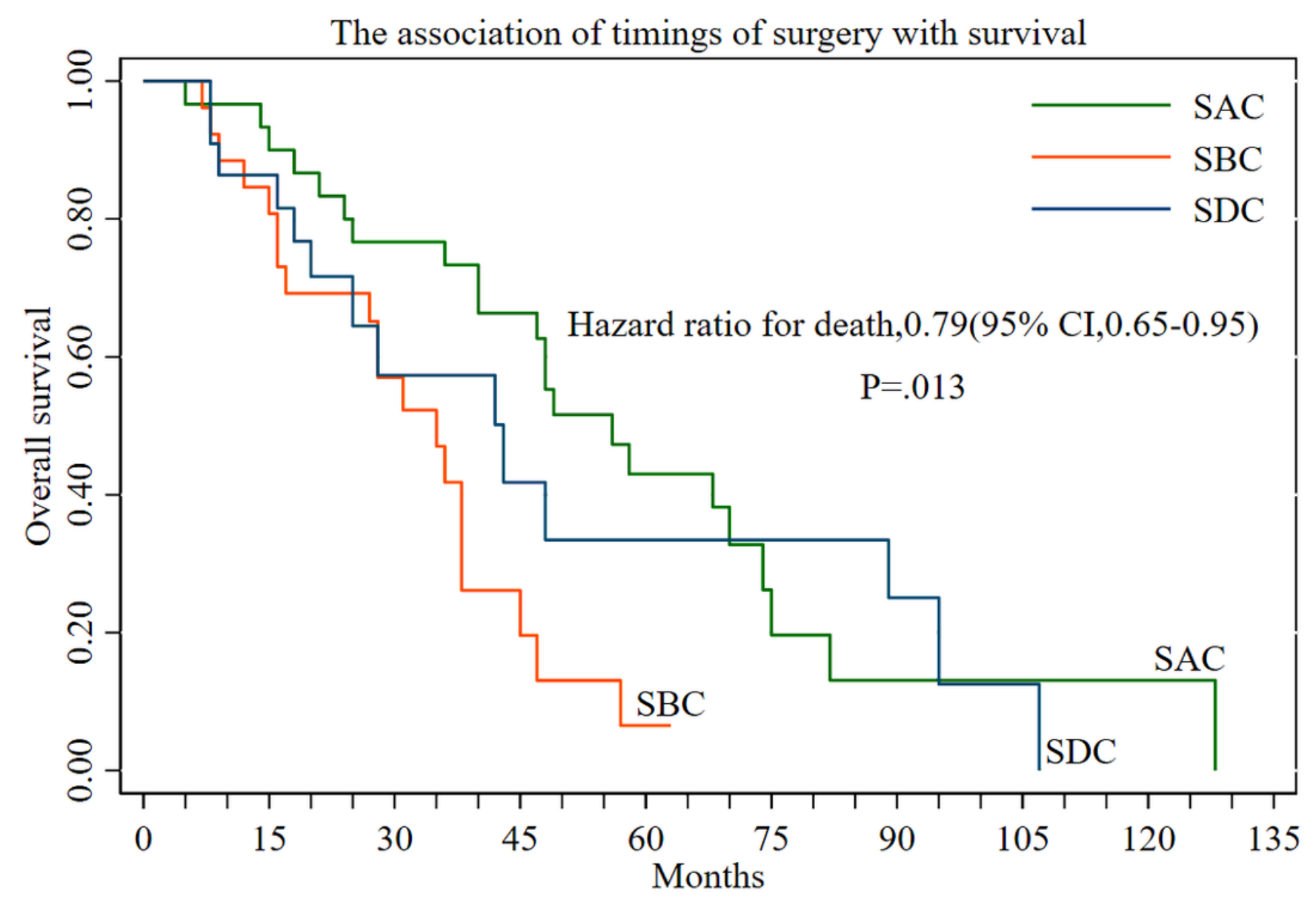

No. at risk

$\begin{array}{ccccccccccc}\text { SAC } & 30 & 28 & 23 & 19 & 9 & 4 & 2 & 1 & 1 & 0 \\ \text { SBC } & 26 & 22 & 13 & 4 & 1 & 0 & 0 & 0 & 0 & 0 \\ \text { SDC } & 22 & 18 & 8 & 5 & 4 & 4 & 3 & 1 & 0 & 0\end{array}$

Figure 3

The association of timings of surgery with survival in patients with de novo metastatic breast cancer. 


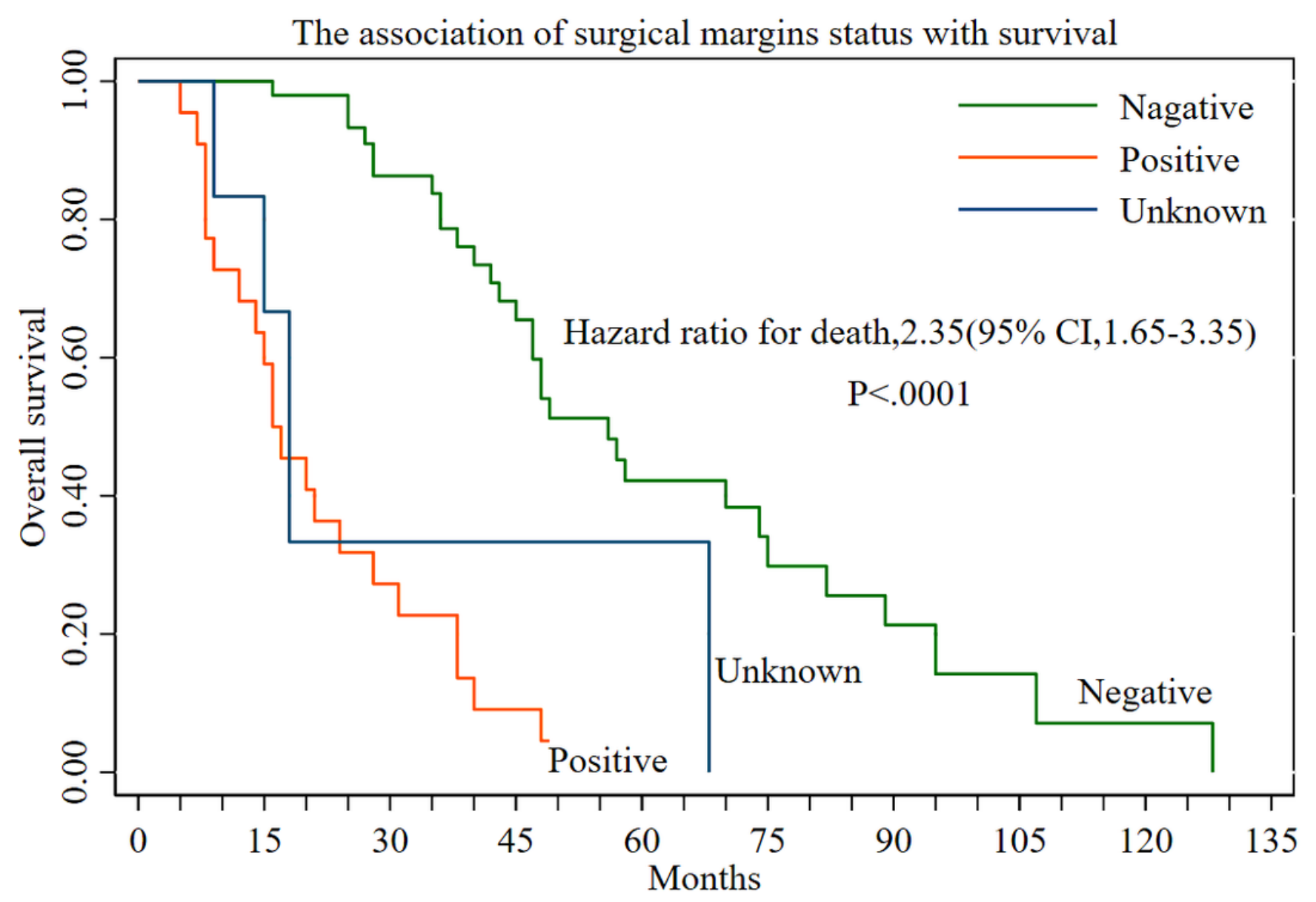

No. at risk

Negative 50

Positive 22

Unknown 6

49

14

5

$\begin{array}{cc}36 & 25 \\ 6 & 2 \\ 2 & 1\end{array}$

13

0

$8 \quad 5$

2

10

$0 \quad 0$

0

0

0

\section{Figure 4}

The association of surgical margins status with survival in patients with de novo metastatic breast cancer. 


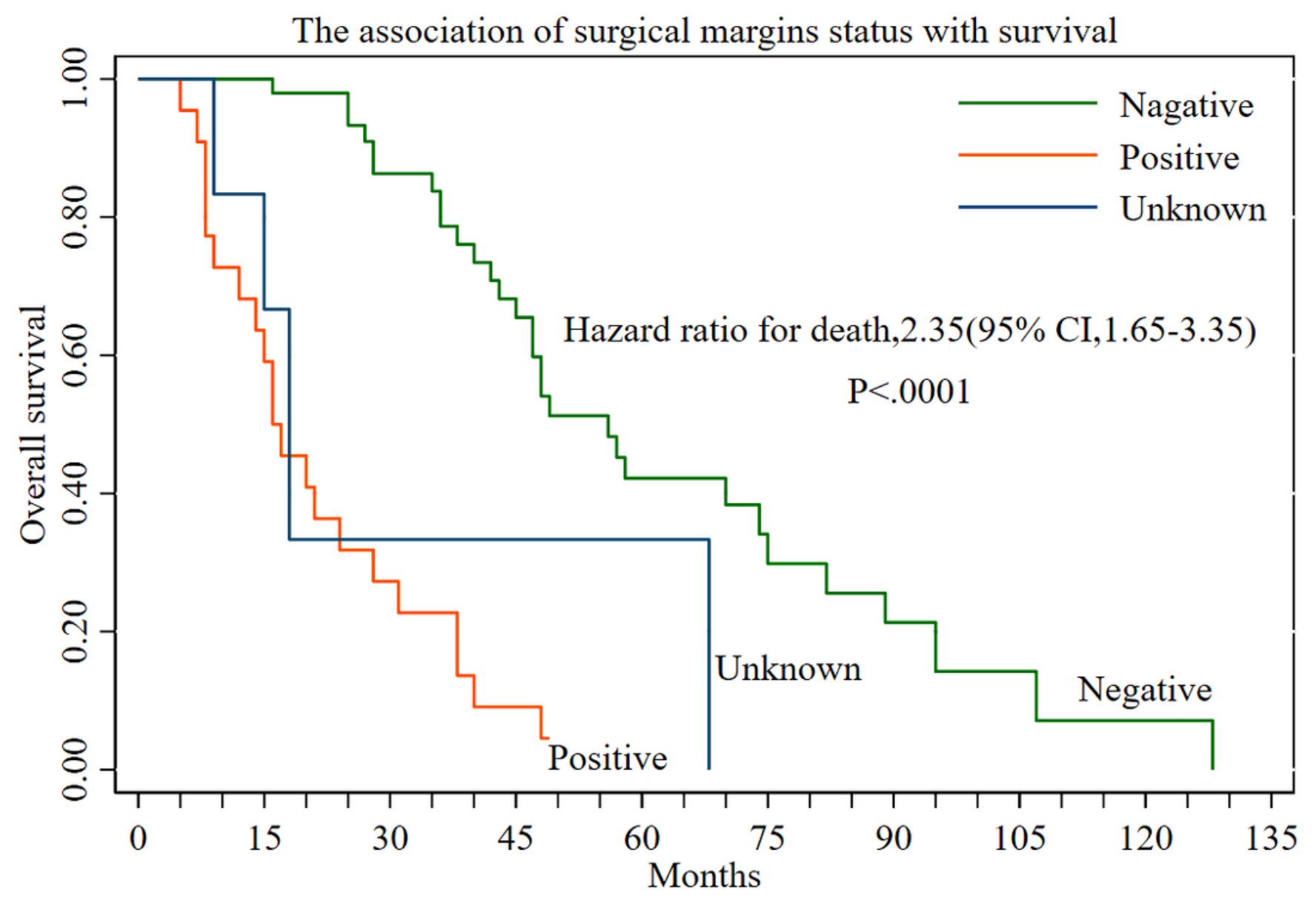

No. at risk

Negative 50

Positive 22

Unknown 6

49

14

5

$\begin{array}{cc}36 & 25 \\ 6 & 2 \\ 2 & 1\end{array}$

13

0

$8 \quad 5$

2

10

1

1

$0 \quad 0$

0

0

0

\section{Figure 4}

The association of surgical margins status with survival in patients with de novo metastatic breast cancer. 


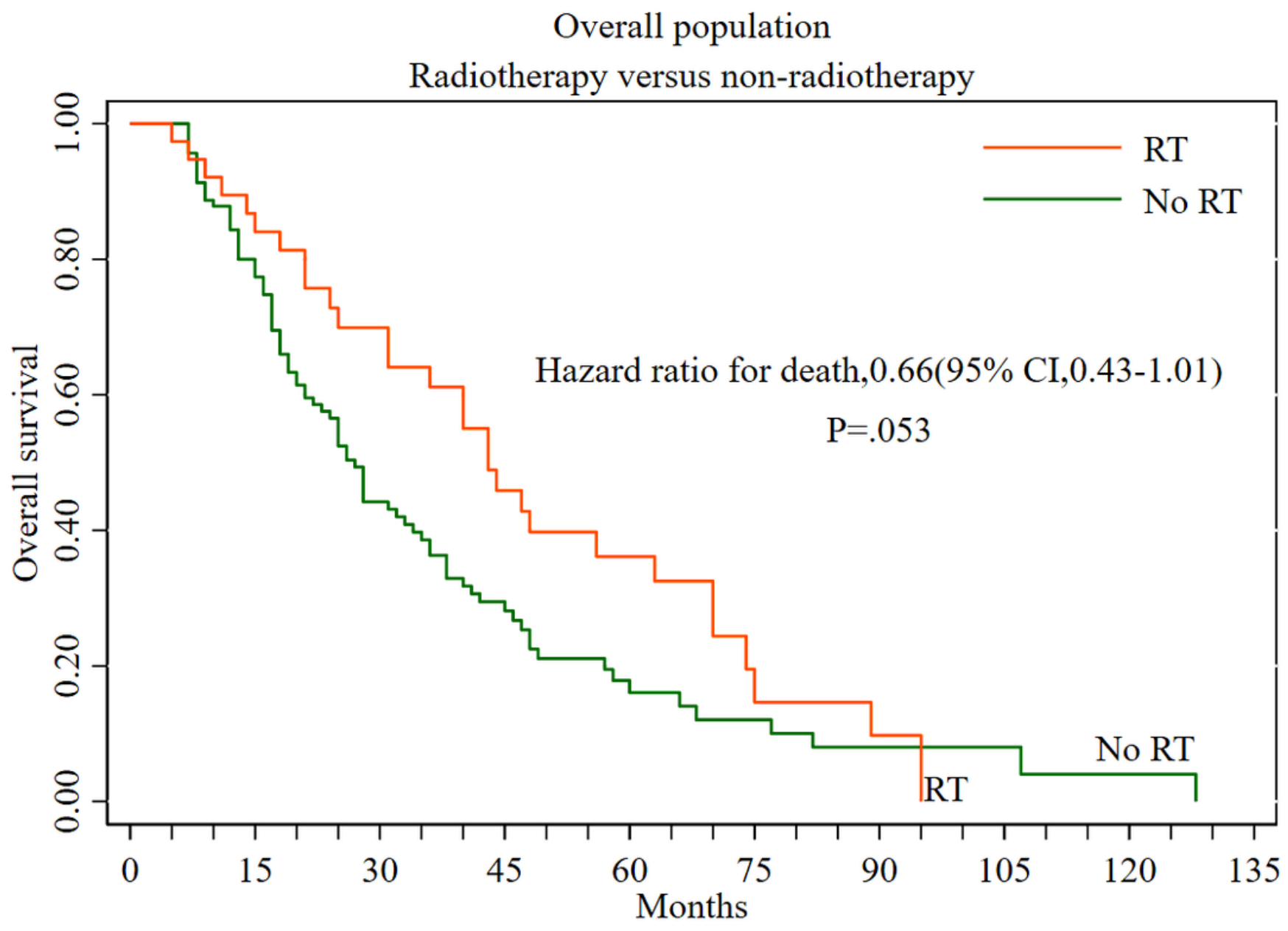

No. at risk

$\begin{array}{rrrrrrrrrrr}\text { No RT } & 115 & 92 & 42 & 22 & 10 & 6 & 3 & 2 & 1 & 0 \\ \text { RT } & 38 & 32 & 24 & 15 & 10 & 4 & 2 & 0 & 0 & 0\end{array}$

Figure 5

Overall survival in patients with de novo metastatic breast cancer were assessed to receive either radiotherapy (RT) or non-radiotherapy (No RT). 


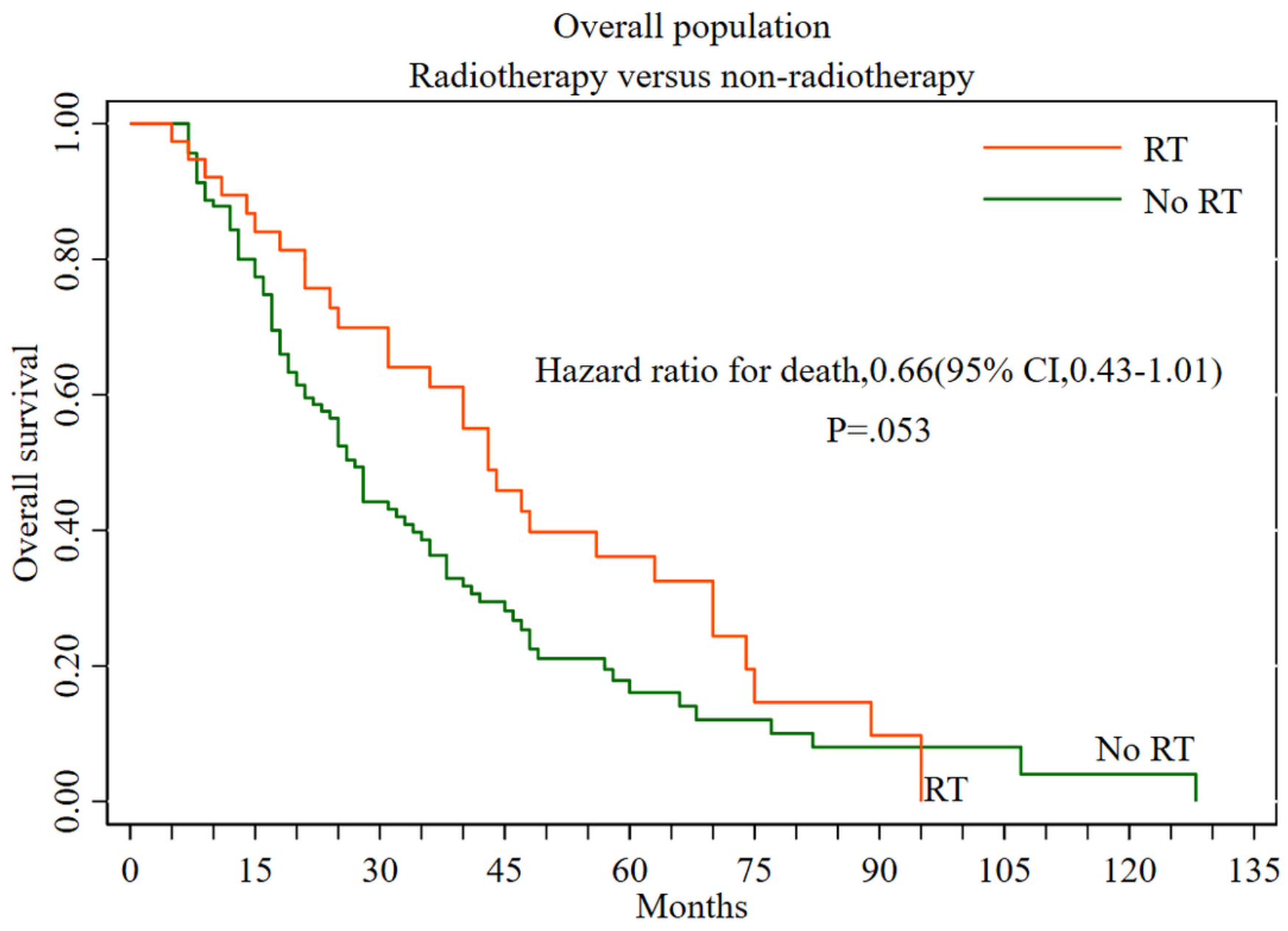

No. at risk

$\begin{array}{rrrrrrrrrrr}\text { No RT } & 115 & 92 & 42 & 22 & 10 & 6 & 3 & 2 & 1 & 0 \\ \text { RT } & 38 & 32 & 24 & 15 & 10 & 4 & 2 & 0 & 0 & 0\end{array}$

Figure 5

Overall survival in patients with de novo metastatic breast cancer were assessed to receive either radiotherapy (RT) or non-radiotherapy (No RT). 


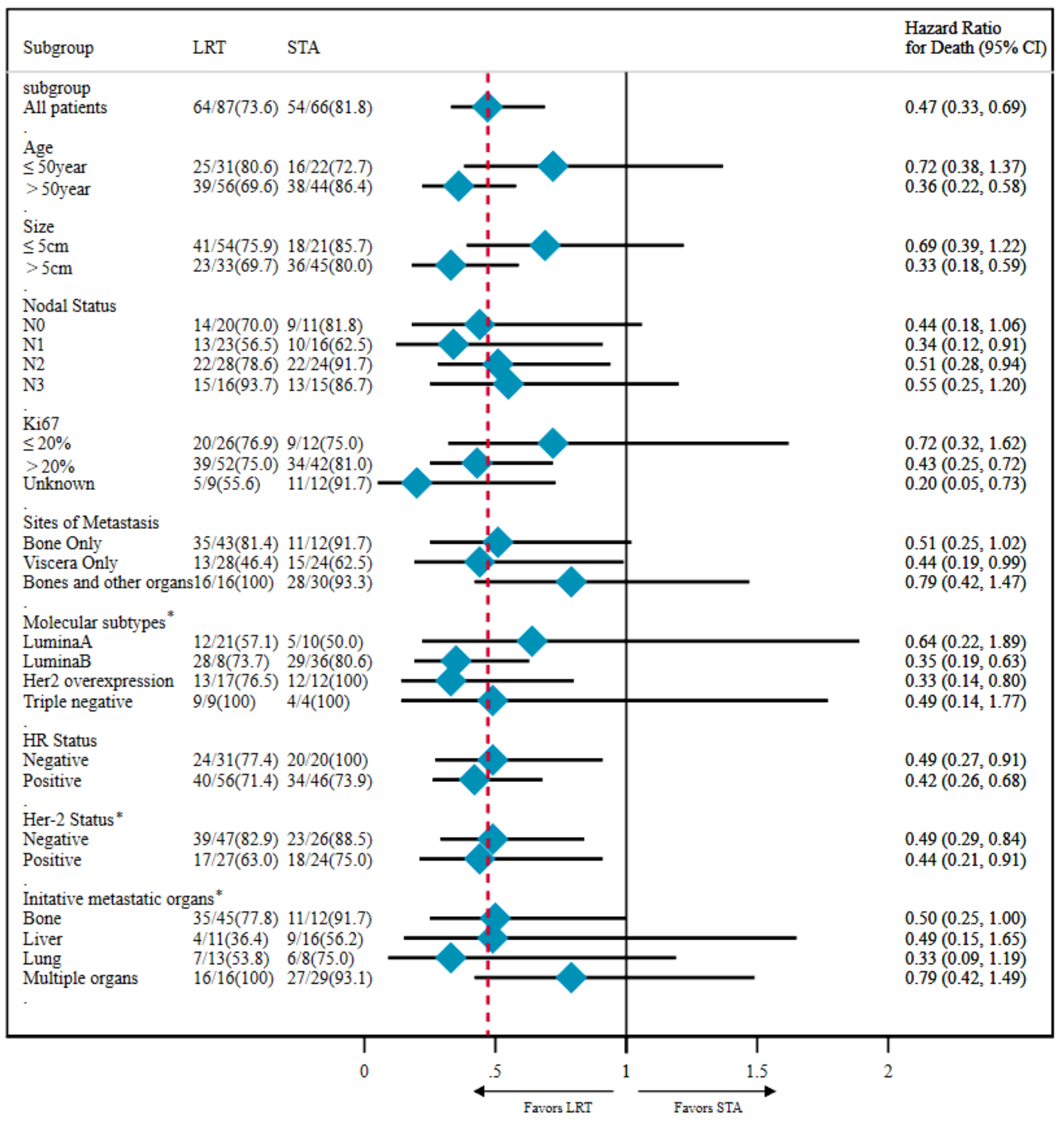

Figure 6

Exploratory analyses of overall survival in subgroups. The solid vertical line shows the no-effect point, and the dashed vertical line indicates the hazard ratio of 0.47 for the overall population. Hazard ratios were estimated on the basis of a stratified Cox proportional-hazards model, except in subgroups related to stratification factors, for which an unstratified analysis was used. Subgroup data are based on case-report forms. The hazard ratios for some subgroups had wide confidence intervals owing to the 
small number of patients. HR denotes hormone receptor, and Her2 human epidermal growth factor receptor-2. (*)Percentages may not add up to 100 in that the unknown indexes or missing data in some patients were not included in the subgroup analysis.

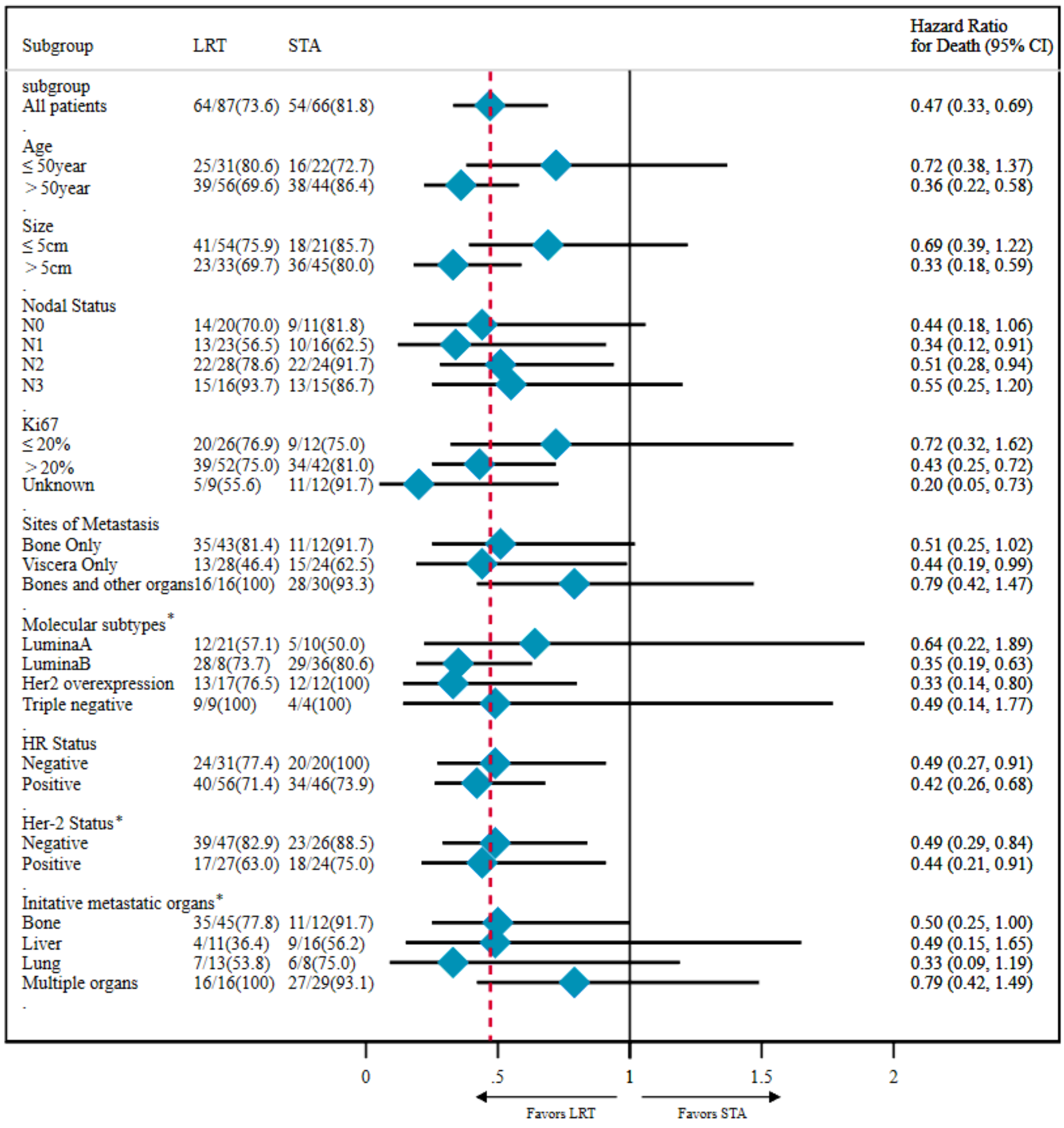

Figure 6

Exploratory analyses of overall survival in subgroups. The solid vertical line shows the no-effect point, and the dashed vertical line indicates the hazard ratio of 0.47 for the overall population. Hazard ratios 
were estimated on the basis of a stratified Cox proportional-hazards model, except in subgroups related to stratification factors, for which an unstratified analysis was used. Subgroup data are based on case-report forms. The hazard ratios for some subgroups had wide confidence intervals owing to the small number of patients. HR denotes hormone receptor, and Her2 human epidermal growth factor receptor-2. (*)Percentages may not add up to 100 in that the unknown indexes or missing data in some patients were not included in the subgroup analysis. 